\title{
Tratamento industrial em sementes de soja: qualidade fisiológica e desempenho da cultura
}

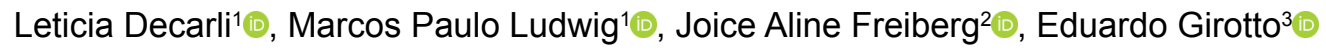 \\ ${ }^{1}$ Instituto Federal de Educação, Ciência e Tecnologia do Rio Grande do Sul, Ibirubá, RS, Brasil. E-mail: leticia.decarli95@gmail.com; marcos.ludwig@ibiruba.ifrs.edu.br \\ ${ }^{2}$ Universidade Federal de Santa Maria, Santa Maria, RS, Brasil. E-mail: joice.freiberg@hotmail.com \\ ${ }^{3}$ Instituto Federal de Educação, Ciência e Tecnologia do Rio Grande do Sul, Bento Gonçalves, RS, Brasil. E-mail: eduardo.girotto@bento.ifrs.edu.br
}

RESUMO: O objetivo deste trabalho foi avaliar a qualidade fisiológica e o desempenho a campo da cultura da soja submetida ao tratamento de sementes industrial e convencional. Sementes de soja das cultivares FPS Urano RR, Syn 1059 RR e Syn 1163 RR

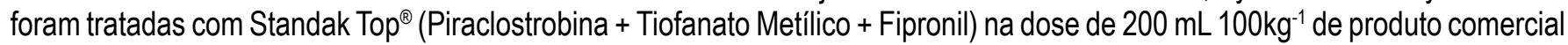

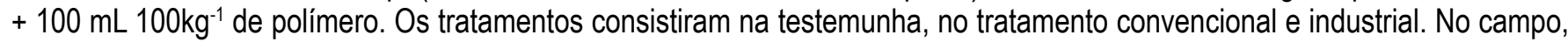
foram avaliadas em duas épocas de semeadura, a emergência, a massa seca e a produtividade de grãos. No laboratório, após 0 tratamento e no $30^{\circ}$, no $90^{\circ}$ e $150^{\circ}$ dias de armazenamento, foram avaliadas a cobertura das sementes e a qualidade fisiológica (teste de germinação, primeira contagem de germinação e emergência de plântulas). 0 tratamento de sementes industrial e convencional não afeta a germinação de sementes de alto vigor (Cultivares Syn 1059 e Syn 1163) e aumenta o percentual de plântulas normais em sementes de baixo vigor (Cultivar FPS Urano). $O$ tratamento de sementes industrial e convencional com Piraclostrobina + Tiofanato Metílico + Fipronil e polímero melhora a emergência da cultura da soja, e potencializa a produtividade de grãos em sementes de cultivares de soja com alta qualidade fisiológica.

Palavras-chave: emergência; germinação; Glicine max (L.) Merril; rendimento de grãos; tratamento de sementes

\section{Industrial treatment in soybean seeds: physiological quality and culture performance}

ABSTRACT: This study aimed to evaluate the physiological quality and the crop performance of soybean seeds submitted to the industrial and the conventional seed treatment process. Soybeans seeds of the cultivars FPS Urano RR, Syn 1059 RR and

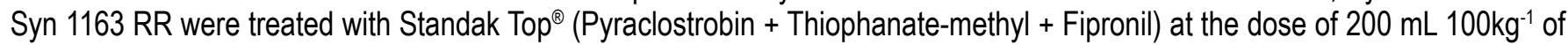

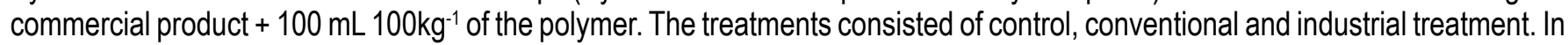
the field, we evaluated the emergence, the dry mass and the grain yield in two times of sowing. Seed coverage and physiological quality of seeds (germination tests, first count of germination and seedling emergence) were evaluated at the laboratory after treatment and at 30,90 and 150 days of storage. Conventional and industrial seed treatment does not affect the germination of high vigor seeds (Cultivars Syn 1059 and Syn 1163) and increases the percentage of normal seedlings in low vigor seeds (Cultivar FPS Urano). The industrial and conventional seed treatment improve the emergence of the soybean crop and potentiates grain yield in soybean cultivars of high physiological quality.

Key words: emergence; germination; Glicine max (L.) Merril; grain yield; seed treatment 


\section{Introdução}

O uso de tecnologias que proporcionam condições mais adequadas aos processos de germinação e emergência das sementes são essenciais para expressar o máximo potencial produtivo das culturas. Nesse sentido, o tratamento químico de sementes tem melhorado a qualidade sanitária e proporcionado proteção contra patógenos, que causam efeitos deletérios às plântulas (Balardin et al., 2011; Conceição et al., 2014) e reduzem o estabelecimento inicial de plântulas no campo (Castro et al., 2008; Mertz et al., 2009; Pereira et al., 2011).

Buscando otimizar a logística, aumentar o rendimento dos equipamentos e maximizar a produtividade das culturas, tem-se observado uma crescente utilização do tratamento de sementes industrial (TSI), principalmente para a cultura da soja (Brzezinski et al., 2015). O tratamento de sementes industrial apresenta algumas vantagens que podem justificar a sua crescente utilização. Dentre elas, podem ser destacadas: i) comodidade aos produtores; ii) maior rendimento por hora; iii) economia de mão de obra e de tempo; iv) diminuição do risco de intoxicação ao produtor, que evita o manuseio com agrotóxicos; v) precisão de aplicação em relação à dose correta dos produtos; e vi) melhor eficiência na cobertura das sementes com os produtos químicos (França-Neto et al., 2015).

Nesse contexto, a avaliação do efeito do tratamento industrial de sementes na qualidade fisiológica, no desenvolvimento da cultura e na produtividade é de grande importância, tendo em vista a crescente utilização de sementes de soja tratadas pelo processo industrial. Estudos prévios têm demonstrado o efeito positivo do tratamento químico de sementes de soja com fungicida (Carbendazim + Tiram) (Mertz et al., 2009) e com fungicida/inseticida (Piraclostrobina + Tiofanato metílico + Fipronil) (Brzezinski et al., 2015) na emergência da cultura. No entanto, apesar do tratamento químico favorecer o estabelecimento de plântulas, ele não tem proporcionado incremento na produtividade de grãos (Rezende et al., 2003; Brzezinski et al., 2015). Além disso, o desempenho inicial de plântulas pode ser reduzido em função da aplicação de produtos químicos como fungicida (Fludioxonil + Metalaxil) e inseticida (Tiametoxam) (Ludwig et al., 2015), em virtude do efeito fitotóxico causado às sementes de soja durante o armazenamento (Conceição et al., 2014). Até o momento, as pesquisas não têm elucidado os efeitos do tratamento industrial de sementes em relação ao tratamento convencional (on farm), realizado por muitos produtores em suas propriedades. Diante do exposto, este estudo buscou avaliar a qualidade fisiológica e o desempenho da cultura da soja submetida ao tratamento de sementes industrial e convencional.

\section{Material e Métodos}

O experimento foi realizado em dois locais do município de Ibirubá: na Cooperativa Agrícola Mista General Osório (Cotribá), onde foram aplicados os tratamentos das sementes; posteriormente, o estudo foi conduzido no Laboratório Didático e de Pesquisa de Sementes e Grãos e na Área Experimental
Didática do Instituto Federal de Educação Ciência e Tecnologia do Rio Grande do Sul - Campus Ibirubá, onde foram realizadas as avaliações de laboratório e os experimentos de campo.

Sementes das cultivares de soja FPS Urano RR com ciclo de maturação 6.2, Syn 1059 RR com ciclo de maturação 5.9 e Syn 1163 RR com ciclo de maturação 6.3 foram submetidas a três tratamentos: (1) testemunha, sem tratamento de sementes; (2) convencional, pelo processo de fluxo contínuo (MTS 120 Especial $^{\circ}$ ) e (3) industrial, com uma máquina modelo ARKTOS AFRICA L4OK ${ }^{\circ}$, que trata as sementes por batelada. As sementes foram tratadas com um volume de calda de 600 $\mathrm{mL} 100 \mathrm{~kg}^{-1}$ de sementes com Standak Top ${ }^{\circledR}$ (Piraclostrobina + Tiofanato Metílico + Fipronil) na dose de $200 \mathrm{~mL} 100 \mathrm{~kg}^{-1}$

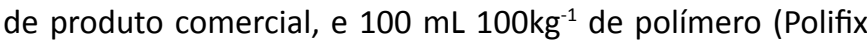
G4). Após o tratamento, as sementes foram armazenadas no laboratório da instituição sob condições não controladas.

No laboratório, o experimento foi conduzido em delineamento experimental inteiramente casualizado, com quatro repetições. As análises de germinarão e primeira contagem de germinação foram realizadas logo após o tratamento de sementes e no $30^{\circ}$, no $90^{\circ}$ e no $150^{\circ}$ dia de armazenamento. $\mathrm{O}$ teste de germinação foi realizado através da semeadura de quatro subamostras de 50 sementes, totalizando 200 sementes por repetição. As sementes foram distribuídas sobre papel germitest umedecido com água destilada na proporção de 3,0 vezes a massa do substrato de papel seco. Posteriormente, os rolos de papel permanecerem no germinador a temperatura de $25{ }^{\circ} \mathrm{C}$. As avaliações foram realizadas oito dias após a semeadura, de acordo com as Regras para Análise de Sementes (Brasil, 2009), e os resultados expressos em porcentagem de plântulas normais. O teste para a primeira contagem de germinação foi realizado conjuntamente ao teste de germinação, sendo a contagem das plântulas normais executada ao quinto dia após o início do teste e os resultados expressos em porcentagem de plântulas normais (Brasil, 2009).

A cobertura das sementes foi determinada visualmente, classificando-as quanto à porcentagem de área revestida pelo polímero, conforme a tabela proposta por Burris (s.d.). Para esta determinação, foram utilizadas 10 sementes de cada unidade experimental.

As sementes armazenadas também foram submetidas às análises de emergência de plântulas em canteiro e matéria seca da parte aérea, conduzidas sob o delineamento em blocos ao acaso com quatro repetições. A emergência de plântulas em canteiro foi realizada com quatro repetições de 100 sementes, as quais foram semeadas em linhas de 1,0 m de comprimento, com espaçamento de 0,20 m entre linhas e dispostas a uma profundidade de 0,03 m. A avaliação da porcentagem de emergência das plântulas foi efetuada aos 21 dias após a semeadura, sendo consideradas as plântulas com cotilédones acima de 0,02 m do nível do solo (Nakagawa, 1994). A massa seca foi determinada aos 21 dias após a semeadura, através da coleta de 10 plântulas no centro de cada linha de semeadura. As plântulas foram lavadas e acondicionadas em estufa de circulação de ar forçado à 
temperatura de $65,5^{\circ} \mathrm{C}$ até atingirem peso constante. Após a pesagem da massa seca, o peso total foi dividido pelo número de plântulas para a obtenção do peso médio das plântulas.

O experimento de campo foi conduzido no período de novembro de 2014 a maio de 2015, na área experimental da instituição, sob as coordenadas $28^{\circ} 37^{\prime} 39^{\prime \prime}$ de latitude Sul e $53^{\circ} 05^{\prime} 23^{\prime \prime}$ de longitude Oeste. O local situa-se na Bacia Hidrográfica do Alto Jacuí, região fisiográfica do Planalto Médio, onde o clima é caracterizado como Cfa subtropical úmido (Peel et al., 2007) e o solo é do tipo Latossolo Vermelho Distroférrico típico (Embrapa, 2013).

A semeadura direta da cultura da soja foi realizada sob sistema plantio direto. A primeira ocorreu no dia 19 de novembro de 2014, e a segunda em 19 de dezembro de 2014, 30 dias após o tratamento das sementes. As parcelas foram constituídas por sete linhas com sete metros de comprimento, espaçadas em $0,45 \mathrm{~m}$ e dispostas sob delineamento de blocos ao acaso com quatro repetições. Dados referentes a precipitação e à temperatura são apresentados na Figura 1.

As avaliações em campo compreenderam: emergência de plântulas, massa seca da parte aérea de plantas e produtividade de grãos. A emergência de plântulas foi avaliada em duas linhas de $3 \mathrm{~m}$ em cada unidade experimental, através da contagem direta das plântulas emergidas aos 14 e 28 dias após a semeadura (DAS), sendo considerada como plântula emergida aquela com cotilédones acima de 0,02 $\mathrm{m}$ do nível do solo. A massa seca foi avaliada aos 30 DAS e compreendeu a coleta de plantas em uma linha de 0,5 m. As plantas foram secas em estufa de circulação de ar forçado à temperatura de $65,5{ }^{\circ} \mathrm{C}$ até atingirem peso constante, e os resultados expressos em $g_{\text {planta }}{ }^{-1}$. A produtividade de grãos foi determinada através da coleta de plantas em três linhas centrais de $3 \mathrm{~m}$ de comprimento. Após a trilha mecânica das plantas, realizaram-se a limpeza, a determinação da massa de grãos ( $\left.\mathrm{kg} \mathrm{ha}^{-1}\right)$ e a correção desse valor para o grau de umidade de $13 \%$ (Conceição et al., 2014).

Os dados foram submetidos à análise de variância e, quando significativos, as médias foram comparadas pelo teste de Tukey a $5 \%$ de probabilidade de erro ou analisadas por regressão em caso de efeito dos tempos de armazenamento. As análises foram realizadas com auxílio do software SISVAR (Ferreira, 2011).

\section{Resultados e Discussão}

Durante o armazenamento, a qualidade fisiológica das sementes de soja reduziu linearmente em função do aumento do período de armazenamento. O fator época $(p=0,000)$ ocasionou uma redução de $32 \%$ e $65 \%$ no percentual de plântulas normais ao final do período de armazenamento, para o teste de germinação e primeira contagem de germinação, respectivamente (Figura 2). Considerando a interação entre época e cultivar (Figura 3), observou-se que a cultivar Syn 1059 manteve o percentual de germinação acima de $80 \%$ até o $150^{\circ}$ dia de armazenamento. Contudo, houve uma redução significativa da qualidade fisiológica das cultivares FPS Urano e Syn 1163. Essa redução pode estar relacionada a diferentes fatores que ocasionam a deterioração das sementes durante o armazenamento, como o teor de água das sementes, o ataque de fungos e insetos, o efeito fitotóxico dos produtos, a qualidade fisiológica inicial dos lotes e as condições de armazenamento (Marcos-Filho, 2015; Ferreira et al., 2016).

O tratamento de sementes reduziu significativamente a qualidade fisiológica das cultivares (Tabela 1). Destacamos que a cultivar FPS Urano apresentou os menores valores de plântulas normais, principalmente nas sementes sem

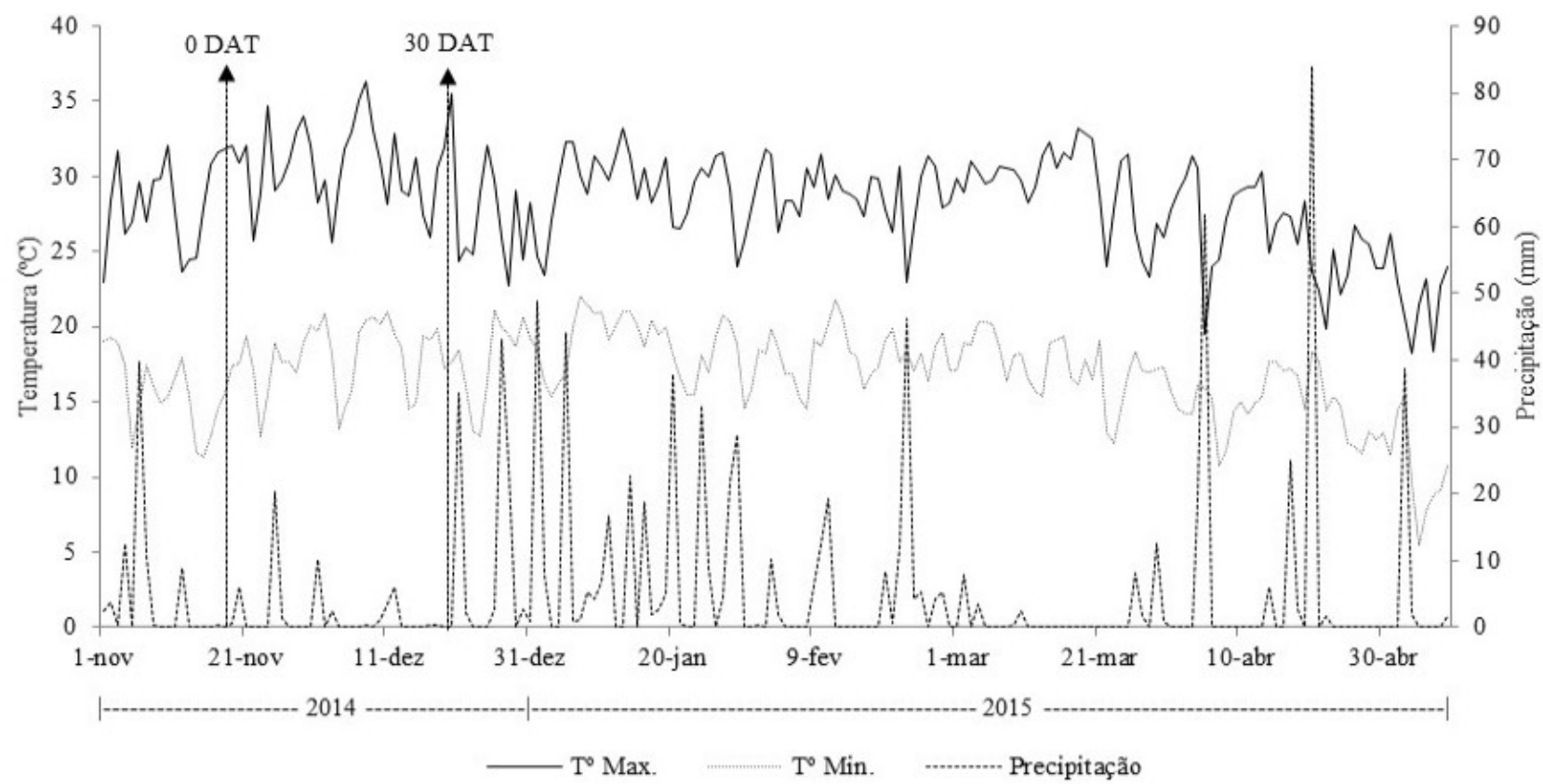

Figura 1. Precipitação $(\mathrm{mm})$ e temperatura máxima e mínima $\left({ }^{\circ} \mathrm{C}\right)$ durante o desenvolvimento da cultura da soja na área experimental do IFRS - Campus Ibirubá. 0 DAT e 30 DAT indicam o momento da semeadura (dias) após o tratamento de sementes. Dados obtidos da Estação Automática de Ibirubá - A883. Ibirubá/RS, 2014-2015. 


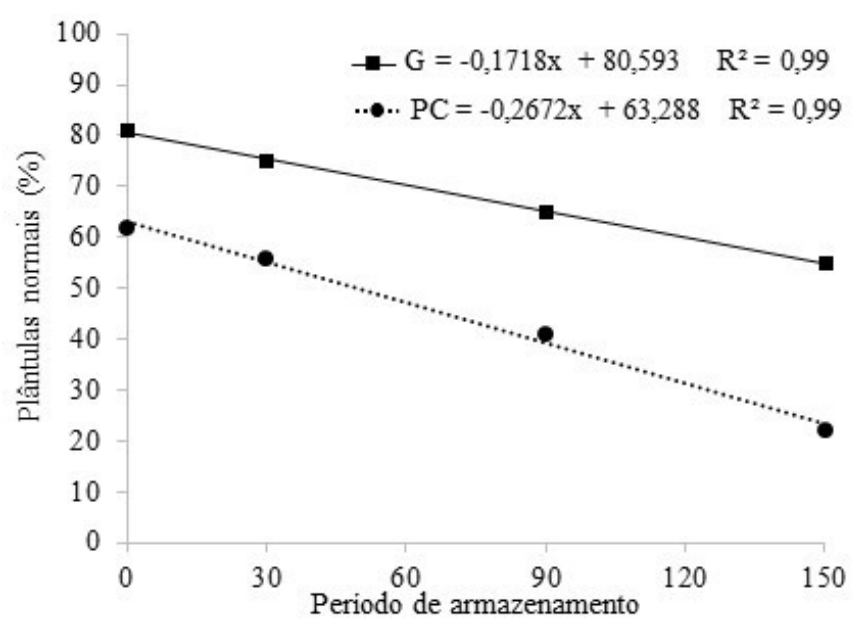

Figura 2. Germinação (G) e primeira contagem de germinação (PC) de três cultivares de soja submetidas a três tratamentos de sementes (testemunha, convencional e industrial) e armazenadas durante 150 dias.

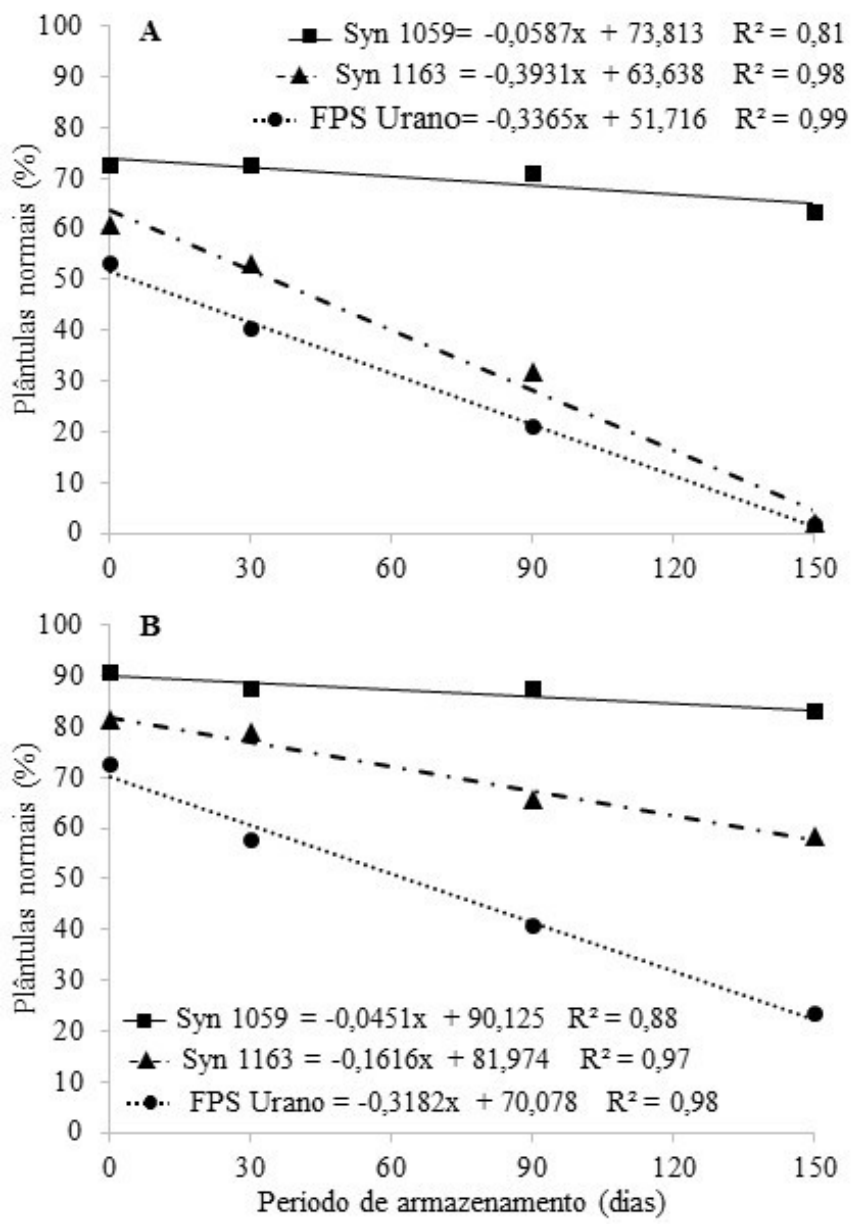

Figura 3. Primeira contagem de germinação (PC) (A) e germinação (G) (B) de três cultivares de soja submetidas a três tratamentos de sementes (testemunha, convencional e industrial) e armazenadas durante 150 dias.

tratamento (testemunha). A cultivar Syn 1059 apresentou os maiores valores, embora não tenha apresentado diferenças significativas entre os tratamentos. Da mesma forma, o tratamento de sementes não afetou a qualidade
Tabela 1. Primeira contagem de germinação (\%) e germinação de sementes (\%) de três cultivares de soja submetidas a três tratamentos de sementes (testemunha, convencional e industrial), na média de avaliações após o tratamento, 30, 90 e 150 dias de armazenamento. Ibirubá/RS, 2014-2015.

\begin{tabular}{lccc}
\hline Tratamento & FPS Urano & Syn 1163 & Syn 1059 \\
\hline & \multicolumn{2}{c}{ Primeira contagem } \\
Testemunha & $21 \mathrm{Cb}$ & $39 \mathrm{Ba}$ & $74 \mathrm{Aa}$ \\
Convencional & $35 \mathrm{Ba}$ & $38 \mathrm{Ba}$ & $68 \mathrm{Aa}$ \\
Industrial & $31 \mathrm{Ba}$ & $36 \mathrm{Ba}$ & $68 \mathrm{Aa}$ \\
Média & $29 \mathrm{C}$ & $38 \mathrm{~B}$ & $70 \mathrm{~A}$ \\
CV (\%) & \multicolumn{4}{c}{ Germinação } \\
\hline \multicolumn{4}{c}{$72 \mathrm{Ba}$} \\
Testemunha & $35 \mathrm{Cc}$ & $89 \mathrm{Aa}$ \\
Convencional & $59 \mathrm{Ca}$ & $70 \mathrm{Ba}$ & $86 \mathrm{Aa}$ \\
Industrial & $52 \mathrm{Cb}$ & $71 \mathrm{Ba}$ & $86 \mathrm{Aa}$ \\
Média & $49 \mathrm{C}$ & $71 \mathrm{~B}$ & $87 \mathrm{~A}$ \\
CV (\%) & \multicolumn{4}{c}{8,79} \\
\hline
\end{tabular}

Médias seguidas pela mesma letra maiúscula na linha e minúscula na coluna não diferem pelo teste de Tukey a $5 \%$ de probabilidade de erro.

fisiológica das sementes da cultivar Syn 1163; contudo, houve, respectivamente, uma redução de 46 e $18 \%$ no percentual de plântulas normais na primeira contagem de germinação e na germinação em relação a cultivar Syn 1059. Santos et al. (2018) também observaram comportamentos distintos de cultivares de soja em relação à qualidade fisiológica de sementes armazenadas e tratadas com Piraclostrobina + Tiofanato Metílico + Fipronil e polímero. Destaca-se, também, que estudos têm reportado maior suscetibilidade de sementes de baixo vigor à toxicidade dos produtos químicos utilizados no tratamento de sementes, com efeitos de redução nos percentuais de plântulas normais (Brzezinski et al., 2015). Todavia, nossos resultados demonstram que o tratamento de sementes com Piraclostrobina + Tiofanato Metílico + Fipronil e polímero aumentou o percentual de germinação nas sementes de baixo vigor da cultivar FPS Urano.

O tratamento de sementes industrial proporcionou melhor recobrimento das sementes para as diferentes cultivares de soja (Tabela 2). A aplicação de polímero junto ao tratamento de sementes melhora a aderência e a distribuição dos produtos, proporcionando a obtenção de sementes com melhor recobrimento e coloração (Bays et al., 2007). O recobrimento das sementes das cultivares FPS Urano e Syn 1163 apresentou valores superiores à cultivar Syn 1059 e ao tratamento convencional. O método de tratamento de sementes não apresentou diferença significativa para a cultivar Syn 1059. Ressalta-se que o recobrimento das

Tabela 2. Recobrimento de sementes (escala de 0 a 10) de três cultivares de soja, após o tratamento de sementes industrial e convencional. Ibirubá/RS, 2014-2015.

\begin{tabular}{lccc}
\hline \multicolumn{1}{c}{ Tratamento } & FPS Urano & Syn $\mathbf{1 1 6 3}$ & Syn $\mathbf{1 0 5 9}$ \\
\hline Convencional & $3,03 \mathrm{Bb}$ & $4,35 \mathrm{Ab}$ & $3,43 \mathrm{Ba}$ \\
Industrial & $6,08 \mathrm{Aa}$ & $5,83 \mathrm{Aa}$ & $3,58 \mathrm{Ba}$ \\
Média & & 4,38 & \\
CV (\%) & & 17,7 & \\
\hline
\end{tabular}

Médias seguidas pela mesma letra maiúscula na linha e minúscula na coluna não diferem pelo teste de Tukey a $5 \%$ de probabilidade de erro. 
sementes pode apresentar alta heterogeneidade, sendo necessárias avaliações constantes durante o processo de tratamento de sementes convencional e industrial, bem com novas regulagens para o tratamento de diferentes lotes de sementes (Ludwig et al, 2011).

Em canteiros, aos 21 DAS, o uso de Piraclostrobina + Tiofanato Metílico + Fipronil e polímero aumentou significativamente os percentuais de emergência de plântulas das sementes tratadas pelo processo convencional $(58,2 \%)$ e industrial (51,0\%), quando comparado à testemunha $(44,2 \%)$. As sementes da cultivar FPS Urano obtiveram o menor valor de emergência (36,7\%), seguido das cultivares Syn 1163 (51,5\%) e Syn 1059 (65,1\%). O desempenho distinto das cultivares está condicionado à qualidade fisiológica inicial de cada lote de sementes (Marcos Filho et al., 2009). Em campo, o tratamento de sementes confere alterações benéficas à planta, aumentando sua tolerância ao estresse hídrico e podendo potencializar o rendimento de grãos da cultura da soja (Balardin et al., 2011).

Os percentuais de emergência de plântulas reduziram com o prolongamento do período de armazenamento (dados não apresentados), com percentuais nulos ao final de 150 dias. Nesse período, destaca-se que as condições abióticas de campo - como temperatura e umidade - podem ter prejudicado o processo de germinação das sementes e, consequentemente, a emergência das plântulas.

O processo de tratamento de sementes não afetou o acúmulo de matéria seca das cultivares Syn 1163 e Syn 1059, as quais apresentaram maiores valores após o tratamento de sementes convencional e industrial (Tabela 3). Esses resultados sugerem que sementes de alta qualidade fisiológica podem ser tratadas quimicamente pelo processo convencional e industrial, sem prejuízos ao rendimento de matéria seca. Por outro lado, houve efeito significativo entre o tratamento de sementes e a cultivar FPS Urano, sendo observada uma redução de $15 \%$ e $18 \%$ no acúmulo de matéria seca para os tratamentos de sementes convencional e industrial, respectivamente. A cultivar FPS Urano apresentou baixo vigor, como pode ser observado na análise da primeira

Tabela 3. Matéria seca da parte aérea de plântulas ( g planta $^{-1}$ ) de três cultivares de soja submetidas, aos 21 dias após a semeadura, e submetidas a três tratamentos de sementes (testemunha, convencional e industrial). Ibirubá/RS, 20142015.

\begin{tabular}{lccc}
\hline \multirow{2}{*}{ Tratamento } & \multicolumn{3}{c}{$\begin{array}{c}\text { Matéria seca da parte aérea } \\
\text { de plântulas }\left(\mathrm{g} \mathrm{planta}^{-1}\right)^{*}\end{array}$} \\
\cline { 2 - 4 } & FPS Urano & Syn 1163 & Syn 1059 \\
\hline Testemunha & $0,577 \mathrm{Aa}$ & $0,620 \mathrm{Aa}$ & $0,491 \mathrm{Ba}$ \\
Convencional & $0,491 \mathrm{Bb}$ & $0,647 \mathrm{Aa}$ & $0,536 \mathrm{Ba}$ \\
Industrial & $0,475 \mathrm{Cb}$ & $0,656 \mathrm{Aa}$ & $0,561 \mathrm{Ba}$ \\
Média & 0,514 & 0,641 & 0,529 \\
CV $(\%)$ & & 17,74 & \\
\hline
\end{tabular}

* Valores médios de matéria seca de plântulas após o tratamento de sementes e aos 30, 90 e 150 dias de armazenamento.

Médias seguidas pela mesma letra maiúscula na linha e minúscula na coluna não diferem pelo teste de Tukey a $5 \%$ de probabilidade de erro. contagem de germinação. Brzezinski et al. (2017) reportam que sementes de soja de baixo vigor, tratadas quimicamente com diferentes volumes de calda, apresentaram redução no crescimento de raízes e na parte aérea. Na cultura da aveia preta, o baixo vigor das sementes reduziu o índice de área foliar e a produção de matéria seca sob diferentes populações de plantas (Schuch et al., 2000). Além disso, esses autores observaram menores taxas de crescimento da cultura 29 dias após a emergência. Esses estudos corroboram os resultados obtidos na presente pesquisa, destacando que o baixo vigor das sementes compromete as atividades metabólicas, o potencial de germinação e, principalmente, o crescimento inicial de plântulas (Mondo et al., 2013).

Em campo de produção, os tratamentos convencional e industrial apresentaram maiores valores de emergência em ambas épocas de avaliação (0 e 30 dias após o tratamento), e nas avaliações aos 14 DAS e 28 DAS (Tabela 4). Esse resultado aponta a possibilidade de as sementes serem tratadas e armazenadas por um período de 30 dias, sem prejuízo ao vigor das sementes. Em geral, aos 28 DAS, os tratamentos convencional e industrial apresentaram emergência de plântulas superior à testemunha. Sementes tratadas quimicamente com fungicidas e inseticidas apresentam maior proteção contra o ataque de fitopatógenos e insetos praga (Conceição et al., 2014), protegendo o vigor e proporcionando melhor estabelecimento inicial de plântulas a campo (Nunes, 2016). Dessa forma, a obtenção de um adequado estande de plantas na cultura da soja pode condicionar à obtenção de elevadas produtividades.

Apesar da redução no estande de plantas nas sementes sem tratamento (Tabela 4), não foi verificada diferença entre os métodos de tratamento de sementes para o acúmulo de matéria seca das plantas de soja em pleno florescimento (Tabela 5), bem como nas épocas de semeadura. Ludwig et al. (2015) também não encontraram efeitos do tratamento de sementes com

Tabela 4. Emergência em campo (\%) de três cultivares de soja submetidas a três tratamentos de sementes (testemunha, convencional e industrial), em duas épocas de semeadura (0 e 30 dias após o tratamento de sementes - DAT). Ibirubá/RS, 2014-2015.

\begin{tabular}{lcc}
\hline \multicolumn{1}{c}{ Tratamento } & $\begin{array}{c}\text { Semeadura } \\
\text { O DAT }\end{array}$ & $\begin{array}{c}\text { Semeadura } \\
\text { 30 DAT }\end{array}$ \\
\hline \multicolumn{3}{c}{ Emergência aos 14 DAS } \\
Testemunha & $62,2 \mathrm{~b}$ & $57,7 \mathrm{~b}$ \\
Convencional & $77,0 \mathrm{a}$ & $72,7 \mathrm{a}$ \\
Industrial & $71,4 \mathrm{a}$ & $73,9 \mathrm{a}$ \\
Média & $68,1 \mathrm{a}$ \\
CV (\%) & $70,2 \mathrm{a}$ \\
\hline \multicolumn{3}{c}{12,16} \\
Testemunha & Emergência aos 28 DAS \\
Convencional & $60,3 \mathrm{~b}$ & $55,0 \mathrm{~b}$ \\
Industrial & $75,2 \mathrm{a}$ & $70,9 \mathrm{a}$ \\
Média & $72,6 \mathrm{a}$ & $72,1 \mathrm{a}$ \\
CV (\%) & $69,4 \mathrm{a}$ & $66,3 \mathrm{a}$ \\
\hline
\end{tabular}

Médias seguidas pela mesma letra minúscula na coluna não diferem entre si pelo teste de Tukey a $5 \%$ de probabilidade de erro. 
Tabela 5. Massa seca $\left(\mathrm{kg} \mathrm{ha}^{-1}\right)$ de três cultivares de soja submetidas a três tratamentos de sementes (testemunha, convencional e industrial) em pleno florescimento, na média de duas semeaduras 0 e 30 dias após o tratamento de sementes. Ibirubá/RS, 2014-2015.

\begin{tabular}{cc}
\hline Cultivar & *Massa Seca \\
\hline FPS Urano & $5850 \mathrm{ab}$ \\
Syn 1163 & $6600 \mathrm{a}$ \\
Syn 1059 & $5430 \mathrm{~b}$ \\
Média & 5960 \\
CV (\%) & 21,88 \\
\hline
\end{tabular}

Médias seguidas de mesma letra minúscula não diferem entre si pelo teste de Tukey a $5 \%$ de probabilidade de erro.

*Valores médios das duas épocas de semeadura (0 e 30 dias após o tratamento de sementes - DAT).

fungicida, inseticida, aminoácidos e polímero na massa seca da parte aérea da cultura da soja. Esses trabalhos evidenciam que não há efeito negativo dos produtos na massa seca de plantas. No entanto, houve diferença no acúmulo de massa seca entre as cultivares, com maior acúmulo para a cultivar Syn 1163.

As épocas de semeadura afetaram significativamente a produtividade de grãos. Após o tratamento das sementes (0 DAT) obteve-se uma produtividade média de $3600 \mathrm{~kg} \mathrm{ha}^{-1}$, com redução de $51 \%$ (1843 $\mathrm{kg} \mathrm{ha}^{-1}$ ) da produtividade para a segunda época de semeadura (Tabela 6). Este resultado ressalta a importância de se verificar a recomendação técnica das empresas para as diferentes cultivares, apesar do correto enquadramento da semeadura para o período da cultura. Segundo Meotti et al. (2012), a época de semeadura pode contribuir em média com $76 \%$ da variação total em produtividade de grãos. Além da produtividade, a época de semeadura também interfere na qualidade do grão, através de alterações nos teores de óleo e proteínas (Freiria et al., 2016). A semeadura realizada após o período indicado para a cultura compromete a capacidade fotossintética e o Índice de Área Foliar da cultura, em virtude da redução do fotoperíodo. Com isso, a superfície de assimilação de $\mathrm{CO}_{2}$ e a interceptação de radiação solar convertem menores taxas de fitomassa e crescimento (Ludwig et al., 2015). Quando altas produtividades são almejadas, é fundamental conhecer o

Tabela 6. Produtividade $\left(\mathrm{kg} \mathrm{ha}^{-1}\right)$ de três cultivares de soja submetidas a três tratamentos de sementes (testemunha, convencional e industrial) aos 0 e 30 dias após o tratamento (DAT). Ibirubá/RS, 2014-2015.

\begin{tabular}{|c|c|c|c|}
\hline Tratamento & FPS Urano & Syn 1059 & Syn 1163 \\
\hline \multicolumn{4}{|c|}{ Semeadura 0 DAT } \\
\hline Testemunha & $3536 \mathrm{Aa}$ & $3242 \mathrm{Aa}$ & $3508 \mathrm{Ab}$ \\
\hline Convencional & $2951 \mathrm{Ba}$ & $3777 \mathrm{Aa}$ & $3934 \mathrm{Aab}$ \\
\hline Industrial & $3427 \mathrm{Ba}$ & $3695 \mathrm{Aa}$ & $4328 \mathrm{Aa}$ \\
\hline \multicolumn{4}{|c|}{ Semeadura 30 DAT } \\
\hline Testemunha & $1892 \mathrm{Aa}$ & $1584 \mathrm{Aa}$ & $1582 \mathrm{Aa}$ \\
\hline Convencional & $2044 \mathrm{Aa}$ & $1801 \mathrm{Aa}$ & $1648 \mathrm{Aa}$ \\
\hline Industrial & $1763 \mathrm{Aa}$ & $1932 \mathrm{Aa}$ & $1566 \mathrm{Aa}$ \\
\hline Média & & 2678 & \\
\hline CV (\%) & & 15,11 & \\
\hline
\end{tabular}

Médias seguidas pela mesma letra maiúscula na linha e minúscula na coluna não diferem pelo teste de Tukey a $5 \%$ de probabilidade de erro. clima da região de cultivo, a época de semeadura e o máximo desenvolvimento vegetativo, pois esses fatores podem ser limitantes ao desempenho da cultura da soja (Johann et al., 2016).

Na primeira época de semeadura (0 DAT), o tratamento de sementes industrial potencializou a produtividade da cultivar Syn 1163, apresentando um incremento de $820 \mathrm{~kg} \mathrm{ha}^{-1} \mathrm{em}$ relação à testemunha (Tabela 6 ). 0 melhor recobrimento de sementes verificado nessa cultivar (Tabela 2) pode ter potencializado o seu desempenho produtivo.

$\mathrm{Na}$ semeadura realizada após 30 dias do tratamento de sementes, não foram verificados efeitos do método de tratamento e da utilização de produtos químicos nas sementes. Nesse sentido, este estudo demonstra a ausência de efeito negativo do tratamento de sementes industrial na produtividade da cultura da soja.

\section{Conclusões}

O tratamento de sementes industrial e convencional com Piraclostrobina + Tiofanato Metílico + Fipronil e polímero não afetam a germinação de sementes de alto vigor (Cultivares Syn 1059 e Syn 1163), e aumentam o percentual de plântulas normais em sementes de baixo vigor (Cultivar FPS Urano).

O tratamento de sementes industrial e convencional com Piraclostrobina + Tiofanato Metílico + Fipronil e polímero melhoram a emergência da cultura da soja.

O tratamento de sementes industrial e convencional potencializam a produtividade de grãos em sementes de cultivares de soja com alta qualidade fisiológica.

\section{Agradecimentos}

Ao Conselho Nacional de Desenvolvimento Científico e Tecnológico (CNPq) pela concessão de bolsa de iniciação científica à primeira autora.

\section{Literatura Citada}

Balardin, R.S; Silva, F.D.L. da; Debona, D.; Corte, G.D.; Favera, D.D.; Tormen, N.R. Tratamento de sementes com fungicidas e inseticidas como redutores dos efeitos do estresse hídrico em plantas de soja. Ciência Rural, v.41, n.7, p.1120-1126, 2011. https://doi.org/10.1590/S0103-84782011000700002.

Bays, R.; Baudet, L.; Henning, A.A.; Filho, O.L. Recobrimento de Sementes de Soja com Micronutriente, Fungicida e Polímero. Revista Brasileira de Sementes, v.29, n.2, p.60-67, 2007. https:// doi.org/10.1590/S0101-31222007000200009.

Brasil. Ministério da Agricultura, Pecuária e Abastecimento. Regras para análise de sementes. Brasília: MAPA/ACS, 2009. 399p.

Brzezinski, C.R.; Abati, J.; Henning, F.A.; Henning, A.A.; França-Neto, J. de B.; Krzyzanowski, F.C.; Zucareli, C. Spray volumes in the industrial treatment on the physiological quality of soybean seeds with different levels of vigor. Journal of Seed Science, v. 39, n.2, p. 174-181, 2017. https://doi.org/10.1590/2317$1545 v 39 n 2175179$. 
Brzezinski, C.R.; Henning, A.A.; Abati, J.; Henning, F.A.; França-Neto, J. de B.; Krzyzanowski, F.C.; Zucareli, C. Seeds treatment times in the establishment and yield performance of soybean crops. Journal of Seed Science, v.37, n.2, p.147-153, 2015. https://doi. org/10.1590/2317-1545v37n2148363.

Burris, J. Film coating recovery quality rating scale. Ames: Seed Science Center; lowa State University, s.d. 1p.

Castro, G.S.A.; Bogiani, J.C.; Silva, M.G. da; Gazola, E.; Rosolem, C.A. Tratamento de sementes de soja com inseticidas e um bioestimulante. Pesquisa Agropecuária Brasileira, v.43, n.10, p.13111318, 2008. https://doi.org/10.1590/S0100-204X2008001000008.

Conceição, G.M.; Barbieri, A.P.P.; Lúcio, A.D.; Martin, T.N.; Mertz, L.M.; Mattioni, N.M.; Lorentz, L.H. Desempenho de Plântulas e Produtividade de Soja Submetida a Diferentes tratamentos Químicos nas Sementes. Bioscience. Journal, v.30, n.6, p.1711-1720, 2014. http://www.seer.ufu.br/index.php/ biosciencejournal/article/view/22024. 02 Jul. 2018.

Empresa Brasileira de Pesquisa Agropecuária - Embrapa. Sistema brasileiro de classificação de solos. 3.ed. Brasília: Embrapa, 2013. 306p.

Ferreira, D.F. Sisvar: a computer statistical analysis system. Ciência e Agrotecnologia, v.35, n.6, p.1039-1042, 2011. https://doi. org/10.1590/S1413-70542011000600001.

Ferreira, T.F.; Oliveira, J.A.; Carvalho, R.A. de; Resende, L.S.; Lopes, C.G.M.; Ferreira, V. de F. Quality of soybean seeds treated with fungicides and insecticides before and after storage. Journal of Seed Science, v.38, n.4, p.278-286, 2016. https://doi. org/10.1590/2317-1545v38n4161760.

França-Neto, J. de B.; Henning, A.A.; Krzyzanowski, F.C.; Henning, F.A.; Lorini, I. Adoção do tratamento industrial de sementes de soja no Brasil, safra 2014/2015. Informativo ABRATES, v. 25, p.26-29, 2015. https:// www.alice.cnptia.embrapa.br/alice/bitstream/doc/1019146/1/ adocaodotratamentoindustrioaldesementesdesojanobr.pdf. 17 Ago. 2018.

Freiria, G.H.; Lima, W.F.; Leite, R.S.; Mandarino, J.M.G.; Silva, J.B. da; Prete, C.E.C. Productivity and chemical composition of food-type soybeans sown on different dates. Acta Scientiarum. Agronomy, v.38, n.3, p.371377, 2016. https://doi.org/10.4025/actasciagron.v38i3.28632.

Johann, J.A.; Becker, W.R.; Uribe-Opazo, M.A.; Mercante, E. Uso de imagens do sensor orbital Modis na estimação de datas do ciclo de desenvolvimento da cultura da soja para o estado do Paraná - Brasil. Engenharia Agrícola, v.36, n.1, p.126-142, 2016. https:// doi.org/10.1590/1809-4430-Eng.Agric.v36n1p126-142/2016.

Ludwig, M.P.; Lucca Filho, O. A.; Baudet, L.; Dutra, L. M. C.; Avelar, S. A. G.; Crizel, R. L.; Oliveira, S. de. Eficiência do recobrimento de sementes de soja em equipamento com sistema de aspersão. Ciência Rural, v.41, n.4, p.557-563, 2011. https://doi. org/10.1590/S0103-84782011005000023.

Ludwig, M.P.; Oliveira, S. de; Avelar, S.A.G.; Rosa, M.P.; Lucca Filho, O.A.; Crizel, R.L. Armazenamento de sementes de soja tratadas e seu efeito no desempenho de plântulas. Tecnologia \& Ciência Agropecuária, v.9, n.1, p.51-56, 2015. http://revistatca.pb.gov. br/edicoes/volume-09-2015/volume-9-numero-1-marco-2015/ tca9110.pdf. 25 Set. 2018.
Marcos Filho, J. Seed vigor testing: an overview of the past, present and future perspective. Scientia Agricola, v.72, n.4, p.363-374, 2015. https://doi.org/10.1590/0103-9016-2015-0007.

Marcos-Filho, J.; Kikuti, A.L.P.; Lima, L.B. Métodos para avaliação do vigor de sementes de soja, incluindo a análise computadorizada de imagens. Revista Brasileira de Sementes, v.31, n.1, p.102-112, 2009. https://doi.org/10.1590/S0101-31222009000100012.

Meotti, G.V.; Benin, G.; Silva, R.R.; Beche, E.; Muraro, L.B. Épocas de semeadura e desempenho agronômico de cultivares de soja. Pesquisa Agropecuária Brasileira, v.47, n.1, p.14-21, 2012. https://doi.org/10.1590/S0100-204X2012000100003.

Mertz, M.; Henning, F.A.; Zimmer, P.D. Bioprotetores e fungicidas químicos no tratamento de sementes de soja. Ciência Rural, v.39, n.1, p.13-18, 2009. https://doi.org/10.1590/S010384782009000100003

Mondo, V.H.V.; Cicero, S.M.; Dourado-Neto, D.; Pupim, T.L.; Dias, M.A.N. Seed vigor and initial growth of corn crop. Journal of Seed Science, v.35, n.1, p. 64-69, 2013. https://doi.org/10.1590/ S2317-15372013000100009.

Nakagawa, J. Testes de vigor baseados na avaliação das plântulas. In: Vieira, R.D.; Carvalho, N.M. (Eds.) Testes de vigor em sementes. Jaboticabal: FUNEP, 1994. p.49-85.

Nunes, J.C.S. Tratamento de Sementes de Soja como um Processo Industrial no Brasil. Revista Seed News, v.20, n.1, p.26-32, 2016. https://seednews.com.br/edicoes/artigo/334-tratamento-desementes-de-soja-como-um-processo-industrial-no-brasiledicao-janeiro-2016. 15 Set. 2018.

Peel, M.C.; Finlayson, B.L.; McMahon, T.A. Updated world map of the Köppen-Geiger climate classification. Hydrology and Earth System Sciences, v. 11, n.5, p.1633-1644, 2007. https://doi. org/10.5194/hess-11-1633-2007.

Pereira, C.E.; Oliveira, J.A.; Guimarães, R.M.; Vieira, A.R.; Evangelista, J.R.E.; Oliveira, G.E. Fungicide treatment and film coating of soybean seeds submitted to storage. Ciência e Agrotecnologia, v.35, n.1, p.158-164, 2011. https://doi.org/10.1590/S141370542011000100020.

Rezende, P.M. de; Machado, J. da C.; Gris, C.F.; Gomes, L.L.; Botrel, E.P. Efeito da semeadura a seco e tratamento de sementes na emergência, rendimento de grãos e outras características da soja (Glycine Max (L.) Merrill). Ciência e Agrotecnologia, v.27, n.1, p.7683, 2003. https://doi.org/10.1590/S1413-70542003000100009.

Santos, S.F. dos; Carvalho, E.R.; Rocha, D.K.; Nascimento, R.M. Composition and volumes of slurry in soybean seeds treatment in the industry and physiological quality during storage. Journal of Seed Science, v.40, n.1, p.067-074, 2018. https://doi. org/10.1590/2317-1545v40n1185370.

Schuch, L.O.B.; Nedel, J.L.; Assis, F.N.; Maia, M.S. Vigor de sementes e análise de crescimento de aveia preta. Scientia Agricola, v.57, n.2, p.305-312, 2000. https://doi.org/10.1590/S010390162000000200018 . 